Bráulio TAVARES

\title{
"Levei certo tempo para compreender que os caminhos de autores como Rosa, Pound e Joyce são pessoais. Ninguém tem obrigação de partir do que eles escreveram e avançar alguns passos. Cada um precisa fazer sua própria literatura".
}

Presença marcante na música popular brasileira, Bráulio Tavares tem mais de vinte livros publicados, incluindo romance, conto, crônica, ensaio, poesia e literatura de cordel. Também organizou uma dezena de antologias de literatura fantástica e ficção científica. Igualmente relevante é o rol de obras que traduziu. Conhecidos são ainda seus textos teatrais e roteiros de cinema e televisão.

As perguntas e respostas abaixo reproduzidas resultaram de uma entrevista pública realizada na Faculdade de Letras da UFRJ em setembro de 2016, por ocasião do VII Encontro do Fórum de Literatura Brasileira Contemporânea. A mediação coube a Dau Bastos, que se permitiu colocar questões extremamente simples, certo da capacidade do entrevistado de discorrer com brilho e desenvoltura acerca de qualquer assunto.

De fato, como o leitor pode constatar, cada tópico é motivo de uma explanação longa e consistente, em que a verve e o senso de narratividade sempre se ressaltam, quais provas vivas da qualidade de tudo o que Bráulio produz. O histórico de sua construção como escritor, a singularidade da ficção científica que coloca no papel, a harmonização das múltiplas frentes de criação, a maleabilidade com que desenvolve as parcerias e a prática da literatura de cordel - tudo é tratado com paixão, franqueza e boas pitadas de humor. 
Dau - Bráulio, eu começaria perguntando como se deu sua aproximação com a leitura e a escrita de livros.

Bráulio - Meu avô era jornalista e escrevia sonetos - além de meu pai e dois tios paternos. Meu pai tinha biblioteca e nos aconselhava sobre os livros. Não eram muitos, mas tínhamos sete, oito, dez anos de idade, então, para nós, a estante da sala era demais. Meus pais e minha irmã mais velha liam romances de folhetim, que eram muito vendidos na época. Isso tudo formava uma certa força gravitacional que nos levava nessa direção. Agora, sempre tive muita facilidade para escrever porque nunca houve cobrança. O que havia era uma discussão constante. Daí eu ter desenvolvido uma certa capacidade de verbalização que fez com que logo cedo escrevesse sonetos. Em síntese, senti encantamento com as palavras e, a partir de certo momento, alegria por dominar a escrita.

Dau - Nos últimos dias, andei revisitando seus livros e pensei na possibilidade de você ler para nós o conto "Malassombrado", de A espinha dorsal da memória, lançado em 1989. Se puder falar um pouco sobre essa elogiadíssima coletânea, ficarei ainda mais agradecido.

Bráulio - Certa vez me perguntaram: "Se seus mais de vinte livros fossem destruídos e você só pudesse salvar um, qual seria?" Respondi que seria $A$ espinha dorsal da memória, que considero meu melhor livro (além da continuação dele, chamado Mundo fantasmo). São doze contos que concentram o que tem de melhor em minha prosa. Como dizia Jorge Luis Borges, se algum dia eu tiver que ser julgado pelo que escrevi, espero ser julgado por esse livro e não por um monte de porcaria que publiquei por aí (risos). 
Os livros de contos geralmente começam com uma história longa, que nem todo mundo lê até o fim. Então pensei em abrir com "Malassombrado", que é bem pequenininho:

$\mathrm{Na}$ escura casa da fazenda, os morcegos passavam a noite esvoaçando das paredes para a cumeeira. Eu me encolhia tremendo no fundo da rede, escutando o ruflar solerte das asas de um lado para o outro; puxava as bordas da rede sobre mim, mas aí vinha o temor de que os dentes perfurassem o pano grosso, cravando-se nas minhas costas.

Um dia me disseram que o morcego era um rato de asas. $\mathrm{E}$ nas noites seguintes, quando o medo recrudesceu, imaginei as trevas do quarto sendo invadidas por um enorme gato alado que me libertaria dos pequenos vampiros; imaginei a caçada feroz dentro do casarão, os pequenos corpos negros, estripados, caindo ao chão com um baque surdo. E pensei: extintos os ratos, ficará o gato, como uma onça esvoaçante, farejando mais sangue; e aí terei que sonhar um cachorro também alado e também feroz; e depois outro monstro ainda maior, e outro ainda mais monstro; e as feras cumprirão o seu destino carnívoro de feras, e eu ficarei no escuro fundo da rede, como uma velha a fiar pesadelos.

Dau - Como explicar que você, tão pouco dado às máquinas que sequer dirige automóvel, tenha enveredado pela ficção científica?

Bráulio - Às vezes, a vida nos leva a fazer coisas de que não gostamos muito, mas é sempre melhor você fazer algo de que goste. Tenho muitos amigos que, mesmo não jogando bem, participam 
de peladas no final de semana. O importante é isso. Toque um instrumento, ainda que mal. É ótimo ter um violão velho, um piano, um teclado, uma flauta doce para tocar "Asa branca". Faz bem para a saúde. Ninguém faz isso para ser gênio, para ser o melhor. Agora, quando você faz alguma coisa de que gosta e em que é bom, vai se encaminhando profissionalmente. Na vida adulta, sempre procurei ir em direção às coisas de que gosto: cinema, poesia, música popular brasileira, samba, rock and roll, ficção científica, literatura de terror, literatura policial, as literaturas populares em geral.

Minha geração foi muito marcada pela literatura de vanguarda. Tínhamos quase que obrigação de ser poetas de vanguarda ou prosadores que fossem além de James Joyce. Para nós, os parâmetros de literatura eram Guimarães Rosa, Ezra Pound, James Joyce... Você olhava e dizia: "Como posso ir além desse cara?" Levei certo tempo para compreender que os caminhos de autores como Rosa, Pound e Joyce são pessoais. Ninguém tem obrigação de partir do que eles escreveram e avançar alguns passos. Cada um precisa fazer sua própria literatura. É essa literatura que tem que avançar.

No caso da ficção científica, um dos problemas é que costuma ser relacionada aos Estados Unidos. Mas a pesquiso há muitos anos e, em 2011, publiquei uma antologia intitulada Páginas do futuro: contos brasileiros de ficção científica, em que coloquei narrativas de Joaquim Manuel de Macedo, Raquel de Queiroz e Rubem Fonseca, por exemplo. Todo esse pessoal escreveu ficção científica. O conto da Raquel de Queiroz, "Ma-Hôre”, é maravilhoso. É a história de uma nave que desce num planeta em que há um ser pequenino, meio anfíbio. Começam a brincar com aquela criatura e resolvem trazer para a Terra. O serzinho acaba matando todo mundo, pilota a nave e volta para o planeta dele. Vejo isso e me pergunto em que 
lugar está escrito que só os norte-americanos podem escrever ficção científica. O mesmo acontece com o rock brasileiro. Por que só americano pode fazer rock? Sou carioca ou paraibano, gosto de rock e não posso fazer? Vou fazer, sim. Agora, se farei bem feito é uma história que vai se resolver lá na frente. De qualquer forma, existem modelos literários que por alguma razão nos encantam mais que outros. Para mim, é o caso da ficção científica e da literatura policial, que leio desde os dez, onze anos de idade.

Passo oito, dez, catorze horas por dia em cima de um teclado - porque sou tradutor, jornalista, colaboro na imprensa, faço roteiro para televisão e para o cinema... -, o que é muito cansativo. Quando não estou em um evento como o de hoje ou alguma outra situação atípica, passo o dia no computador. Se não puder fazer algo que me dê prazer pelo menos durante uma parte dessas horas, vira escravidão. Se é para escrever, que seja algo que me dê prazer, porque o enfrentamento físico com o texto é muito cansativo. Imaginar é um fazer mental, mas escrever é físico.

O bom é a parte criativa do trabalho. Gosto de poder olhar e dizer: "Fulano olhou pela janela e viu que um macaco o filmava com um celular". Imagino e depois vou em frente. A imaginação é como um músculo que você precisa exercitar. Se você exercita, ela brota. Até pouco tempo, tive uma coluna em um jornal da Paraíba, cujos textos atualmente estão em meu blog, Mundo fantasmo. Mantive essa coluna diária por mais de treze anos, sem faltar e sem atrasar. Todo dia tinha que escrever uma coisa diferente. Isso é bom, porque você se obriga a exercitar os tais músculos, que de outra forma não exercitaria, pois ficaria na rede dizendo: "Estou esperando uma ideia genial cair sobre mim”. Bom, não há essa ideia. É você que corre atrás da ideia. Quanto mais você corre atrás, mais ideias vêm 
atrás de você. Então, para mim, a ficção científica é parecida com o soneto, o repente, o samba do partido-alto, o blues. Todas essas são coisas de que gosto e trago para o território de meu prazer criativo.

Dau - Ouvi-lo falar de futebol me deixa um tanto surpreso, pois você esbanja vida em tudo que faz, mas, até onde sei, sua atividade é basicamente mental. Não o imagino correndo atrás de uma bola, andando de bicicleta ou malhando numa academia de ginástica...

Bráulio - De fato, sou totalmente desprovido de vocação para atividades físicas. Tanto que uma das coisas que me seduzem é a teoria do transumanismo. Eles querem tornar possível o upload da memória humana para um computador, para um grande HD que possa registrá-la dentro de si e mantê-la viva e em funcionamento. Isso é uma das coisas mais fascinantes que pode aparecer na ficção científica: a possibilidade da imortalidade não do corpo ou da alma, mas da mente, mediante a digitalização do que a gente tem no cérebro. Acho isso muito remoto do ponto de vista científico, mas, como possibilidade, é interessante investigar: muitos autores já escreveram livros imensos sobre um mundo futuro onde só existem mentes digitais. Todos os dramas humanos de aproximação e afastamento, amizade e inimizade, amor e ódio acontecem nessas mentes humanas, dentro de um gigantesco computador de muitos gigabytes de capacidade. Talvez essa seja a única maneira de você superar a falibilidade dessa coisa efêmera que é o corpo. Um corpo dura apenas décadas e vai embora. Aqui mesmo, estamos falando de vários autores cujos corpos já se foram. O que ficou é alguma coisa digitalizada na memória coletiva, na tradição da gente. Isso acontece quando falamos de Guimarães Rosa, Machado de Assis, todas essas pessoas. 
Ontem passei a tarde procurando um trecho de Nelson Rodrigues que queria colocar em um artigo. Era só um parágrafo, mas, quando vi, já eram sete horas da noite e eu estava lendo como um idiota. $\mathrm{O}$ cara estava vivo ali: tinha me pegado pela mão e não largava mais. Existe vida naquilo. Não a vida original do autor, de seu corpo, mas palavras que funcionam como um desencadeador de vida. É para isso que serve a literatura. Drummond dizia que a vida vai aos livros não para se perder lá dentro, e sim para voltar mais rica. Quando a gente começa a ler, formata a cabeça para captar o espírito do autor no momento em que estava escrevendo. É como se realmente fosse um fenômeno mediúnico, ainda que seja meramente semiótico. É a garantia de vida que a gente tem. A ficção científica serve para isso também: para imaginarmos cenários futuros, em que a vida da gente faça sentido.

Dau - Você tem músicas gravadas por meio mundo. Pediria que falasse um pouco sobre sua atividade de compositor.

Bráulio - Vivemos a adolescência na década de 1960, quando aconteceu de tudo na música brasileira e internacional. Havia um tsunami do rock. Tínhamos Bob Dylan, The Rolling Stones, The Beatles, Janis Joplin, Jimi Hendrix. Esses eram não somente os melhores, mas também os mais famosos. Somos de uma época em que os melhores eram também os mais célebres. Hoje, há uma separação total entre essas categorias. Você pegava a lista dos livros mais vendidos e via, durante meses, Gabriel García Márquez, Rubem Fonseca. Não havia padres, autoajuda, livro de colorir, essas besteiras. Somos uma geração privilegiada: a borra que ficou acumulada naquele copo por onde passou muita coisa boa. Não é possível que depois 
de tudo isso não tivesse ficado nada de bom para a gente produzir. Bem, conheço o Rio de Janeiro desde os dezenove anos de idade, mas vim morar aqui com trinta e dois. Foi nessa época que reencontrei muitos amigos lá da Paraíba e de Pernambuco. Tínhamos muita coisa em comum e começamos a fazer música juntos. Isso é muito interessante, porque a literatura e a poesia são ofícios muito solitários, mas a música é um oficio de parceria e nos ensina a trabalhar em conjunto com outra pessoa visando à obra. Não é minha vaidade ou a sua, a gente está produzindo uma terceira coisa que é maior do que eu e do que você. Noto que alguns amigos dedicados à literatura têm muita dificuldade em trabalhar em grupo ou em parceria, algo que aprendi na música, no cinema, no teatro, na televisão: dividir a responsabilidade e a criatividade. Nem sempre é o ideal, claro. Certas ideias preciso desenvolver sozinho, porque talvez só eu entenda; mas há outras que convém que eu chame alguém para realizar comigo.

Tenho vários parceiros musicais, entre eles o Fuba, com quem compus umas trinta, quarenta músicas. São músicas lindíssimas, que mandamos para as cantoras e elas não gravam, então ficam conhecidas só em mesas de bar e no terraço da casa da gente. O Lenine também é um grande parceiro. É um grande músico e um grande letrista. Em muitas parcerias, ao contrário do que muita gente pensa, os dois fazem letra e música. É o que acontece com a gente: eu com meu violão, um lápis e um papel; ele na cadeira em frente, do mesmo jeito. Começamos pensando se vamos fazer uma música de amor, de ficção científica, se vamos contar uma história. Começamos a roteirizar a música e depois seguimos. Às vezes, chego com um pedaço de música já feito e digo: "Olha, escrevi até aqui, mas não sei para onde vai". Depois ele me liga e fala: "Avancei um pouco aquela ideia". É o que a gente chama de parceria Lennon e 
McCartney. Eles também trabalhavam assim. Um fazia a primeira parte da letra e da música e entregava ao outro, que bolava a segunda parte. Depois se reuniam, faziam o refrão, o restante da banda contribuía etc. Isso faz crescer a parceria.

O Lula Queiroga, por exemplo, é da mesma turma do Lenine, lá de Recife, mas, enquanto tenho mais de trinta músicas com o Lenine, nunca fiz uma com o Lula. No entanto, escrevo roteiros e ele filma para a televisão. Nossa parceria funciona muito melhor assim. Sentamos, temos uma ideia, ficamos remexendo na história durante horas, depois escrevo e ele dirige. Funciona às mil maravilhas. Com cada parceiro você vai descobrindo a melhor maneira de dizer as coisas.

Um dia, Lenine e eu estávamos na casa dele, na Urca, e tivemos vontade de fazer uma música de ficção científica. Lembrei que no dia anterior tinha ouvido Dalva de Oliveira cantando "Ave Maria no morro", de Herivelto Martins:

Barracão de zinco

Sem telhado, sem pintura

Lá no morro

Barracão é bangalô

Lá não existe

Felicidade de arranha-céu

Pois quem mora lá no morro

Já vive pertinho do céu

Sim, mas esse é o céu católico, o céu cristão. Pensamos então em dizer que quem mora no morro vive perto do espaço sideral. E fizemos: 
A nave quando desceu, desceu no morro

Ficou da meia-noite ao meio-dia

Saiu, deixou uma gente

Tão igual e diferente

Falava e todo mundo entendia

Os homens se perguntaram

Por que não desembarcaram

Em São Paulo, em Brasília ou Natal?

Vieram pedir socorro

Pois quem mora lá no morro

Vive perto do espaço sideral

Pois em toda a Via-Láctea

Não existe um só planeta

Igual a esse daqui

A galáxia tá em guerra

Paz só existe na Terra

A paz começou aqui

Sete artes e dez mandamentos

Só tem aqui

Cinco sentidos, terra, mar, firmamento

Só tem aqui

Essa coisa de riso e de festa

Só tem aqui

Baticum, ziriguidum, dois mil e um

Só tem aqui 
A nave estremeceu, subiu de novo

Deixou um rastro de luz do meio-dia

Entrou de volta nas trevas

Foi buscar futuras levas

Pra conhecer o amor e a alegria

A nave quando desceu, desceu no morro

Cheia de ET vestido de orixá

Vieram pedir socorro

E se deram vez ao morro

Todo o universo vai sambar...

Nossa ideia era dizer que o morro está mais perto do sistema solar, da galáxia, do universo do que nós aqui ao nível do mar. E também era uma brincadeira com certa linha da ficção americana da qual li dezenas de contos e livros em que os extraterrestres aparecem e dizem que não fizeram contato conosco porque a galáxia é um oceano de paz, enquanto aqui na Terra vivemos matando uns aos outros. É como se estivéssemos ilhados dentro da civilização galáctica por sermos violentos. Então tentamos fazer o contrário: a galáxia está em guerra, os alienígenas chegam aqui, descem o morro e as pessoas estão cantando, praticando esporte, brincando carnaval, se divertindo, vivendo em paz. Eles vão e voltam, se disfarçam, falam nossa língua, se misturam e se perguntam como conseguimos viver em paz.

Claro, com isso não estou querendo provar tese alguma. Trata-se de mera especulação poética. Mas se alguém é capaz de pensar que somos piores do que as outras raças da galáxia, posso imaginar que somos melhores, que temos coisas que eles não têm. A propósito: 
“Ziriguidum 2001" foi o enredo de ficção científica do pernambucano Fernando Pinto, um carnavalesco inteligentíssimo, que deu o título do carnaval de 1985 à Mocidade Independente de Padre Miguel.

Esses são caminhos que você tem. A única coisa de que precisa é de uma ideia. E não digo que necessite ser um prodígio de originalidade. Pode pegar algo mais ou menos do repertório de todo mundo e criar uma variante nova. Gosto muito mais de pegar coisas que já existem e criar variantes do que inventar algo do zero. Acho isso meio pobre, porque é algo que só eu criei. É pequeno. Mas uma variante que eu consiga criar dentro de algo que centenas de pessoas já fizeram acaba por encorpar mais minha pequena contribuição e meu traço de originalidade. Nesse sentido, me identifico com a concepção de Ariano Suassuna e João Cabral de Melo Neto de respeito à tradição. Nossa geração foi criada debaixo de certa obrigação de ser original, de não dever nada a ninguém, de ser um lobo solitário. Isso também é bonito, mas minha tendência natural é trabalhar dentro de uma tradição. Vi um soneto e pensei: "Vou aprender a fazer e tentar criar algo diferente a partir disso".

André Uzeda (UFRJ) - Bráulio, seus textos são maravilhosos para a formação de jovens leitores literários. Os alunos do ensino básico ficam encantados. No Colégio de Aplicação da UFRJ, adotamos A pedra do meio-dia ou Artur e Isadora, O flautista misterioso e os ratos de Hamelin e uma série de outros escritos seus. Em Contando histórias em versos, você assume que desde pequeno tem uma boa relação com a forma e apreço pela tradição. Em minha posição de formador de leitores literários, também valorizo muito isso. Pediria que falasse um pouco sobre seus livros para jovens. 
Bráulio - Escrevi A pedra do meio-dia ou Artur e Isadora aos 25 anos de idade e o publiquei quando tinha 29. Foi a primeira coisa que publiquei em forma de folheto de cordel: é um romance com trinta e duas páginas, feito em sextilhas, num formato tradicional do cordel. Nessa época, eu morava na Paraíba, trabalhava em um jornal, estudava Ciências Sociais na Universidade Federal da Paraíba e só pensava em duas coisas: futebol e cantoria de viola. Então decidi escrever um folheto de cordel.

A história é a seguinte: um rapaz encontra uma moça que precisa desencantar um reino, porque seu pai foi raptado por um monstro. Encontram uma velhinha que lhes dá três objetos mágicos que vão usando ao longo da viagem, para escapar de perigos. Encontram o monstro, têm um duelo final e desencantam o reino. No momento em que esse cordel foi lançado, as pessoas que não me conheciam achavam que eu era um cordelista de verdade, um senhor de sessenta anos, talvez negro ou mulato. Só que eu era um universitário cabeludo de vinte e poucos anos que usava chinelos de pneu e roupas de hippie. Hoje, conheço alguns jovens cordelistas de vinte, trinta, quarenta anos, que são de classe média, têm formação universitária e escrevem muito bem, pois sabem que o mais importante é dominar a técnica e compreender o espírito. Sem essas duas coisas, você só bate na trave.

No caso específico de A pedra do meio-dia ou Artur e Isadora e O flautista misterioso e os ratos de Hamelin, é interessante observar que acabaram virando livros infantis, mas nunca pensei em escrevê-los para crianças. O cordel não é escrito para crianças, e sim para pessoas de oito a oitenta anos. É lido por todo mundo, sem divisão etária. Mais de vinte anos depois, o pessoal de uma editora perguntou se eu tinha algum livro infantil e respondi que não. Ao perguntar se 
eu não tinha nada em versos, lembrei do cordel. Hoje, esse primeiro é meu livro mais vendido. Quanto ao segundo, somente para um projeto do governo vendeu uma edição de duzentos mil exemplares. São meus livros de maior sucesso, mas não foram escritos nem para serem best-sellers, nem para serem livros infantis.

A gente nunca sabe o que vai agradar amplamente. Agora, sempre que começo a escrever um livro, penso: “Mas será que não há ninguém que reconheça que isso é genial? Essa é a coisa mais importante que já foi escrita!" (risos). Se não acredita nisso, você não escreve. Sem um pouco de megalomania, não chega àquela famosa palavra: "Fim", com que fecha o manuscrito. Sem megalomania, não consegue nem mesmo atravessar uma rua. Agora, você só deve cultivar essa megalomania ao redigir o primeiro rascunho, para não achar que é um gênio. Depois disso, precisa virar o chato que puxa as rédeas do gênio, tira os excessos, completa as lacunas, coloca um pouco de ordem onde há muita desordem, coloca um pouco de desordem onde há muita ordem e assim por diante.

Uma vez vi um editor desses livrinhos de bolso de romances femininos dizer que, como seus livros vendiam muito, recebia muitos originais que percebia que eram de intelectuais. Só que sabia que esses intelectuais não gostavam dos livros que publicava, então se perguntava por que enviavam originais. Para vender muito nesse universo, você precisa gostar desse tipo de publicação. Eu, por exemplo, não tenho o menor interesse em escrever uma história de amor daquelas em que a moça se apaixona por um cara mais rico, luta o livro todo e acaba se casando com ele. Se fizesse algo nesse sentido, fatalmente escreveria de uma maneira desdenhosa e o leitor perceberia. Agora, quando escrevo ficção científica é diferente. Não sinto desdém. Pelo contrário, considero a coisa mais impor- 
tante do mundo. Então provavelmente passe ao leitor um pouco de meu entusiasmo pelo gênero.

De volta aos meus dois livros infantis, talvez vendam graças à minha falta de pretensão. O grande erro das pessoas é escrever pretendendo ser best-seller. Você não escreve um best-seller, mas uma história importantíssima para você. 